\title{
Simple tool to evaluate the impact of daylight on building energy consumption
}

\author{
Hviid, Christian Anker; Nielsen, Toke Rammer; Svendsen, Svend
}

Published in:

Proceedings of the 8th Symposium on Building Physics in the Nordic Countries

Publication date:

2008

Document Version

Early version, also known as pre-print

Link back to DTU Orbit

Citation (APA):

Hviid, C. A., Nielsen, T. R., \& Svendsen, S. (2008). Simple tool to evaluate the impact of daylight on building energy consumption. In Proceedings of the 8th Symposium on Building Physics in the Nordic Countries (Vol. 1, pp. 119-126). Danish Society of Engineers, IDA.

\section{General rights}

Copyright and moral rights for the publications made accessible in the public portal are retained by the authors and/or other copyright owners and it is a condition of accessing publications that users recognise and abide by the legal requirements associated with these rights.

- Users may download and print one copy of any publication from the public portal for the purpose of private study or research.

- You may not further distribute the material or use it for any profit-making activity or commercial gain

- You may freely distribute the URL identifying the publication in the public portal 


\title{
Simple tool to evaluate the impact of daylight on building energy consumption
}

\author{
Christian Anker Hviid, Indutrial Ph.D. student, \\ Alectia $\mathrm{A} / \mathrm{S}$; \\ crh@alectia.com
}

Toke Rammer Nielsen, Assoc. prof., Depatment of Civil Engineering, Technical University of Denmark; trn@byg.dtu.dk

\author{
Svend Svendsen, Professor, \\ Department of Civil Engineering, Technical University of Denmark; \\ ss@byg.dtu.dk
}

KEYWORDS: Simulation, daylight, validation, radiosity, integration, building design

\section{SUMMARY:}

This paper presents a simple building simulation tool for integrated daylight and thermal analysis. The tool is capable of importing the thermal and visual properties for different glazings and shading positions from the Window Information System (WIS) program. Radiosity methodology is used to derive the daylight levels for different sky conditions on an hourly basis. The daylight levels are fed into an existing simple thermal simulation program capable of calculating energy demand and the indoor environment. Straightforward control systems for general and task lighting systems have been implemented together with a shading control strategy that adjusts the shading according to the indoor operative temperature and the profile angle of the sun. The implemented daylight calculation method allows for shades from the window recess and overhang. Comparisons with the raytracing program Radiance show that the accuracy of this approach is adequate for predicting the energy implications of photoresponsive lighting control.

\section{Introduction}

For integrated daylight and thermal simulations several approaches and programs have been developed. One approach which is implemented in the program Adeline (Fraunhofer-Institut für Bauphysik 2006) generates an annual output file for lighting which may be used as an internal load file in a thermal simulation program. However, this method lacks interactivity between daylight, lighting, solar shading and the thermal performance of the building. Another approach is to use Radiance (Ward, G.L. and Shakespeare, R.A. 1998) in combination with a thermal simulation program. This approach has been implemented in ESP-r (Clarke, J. and Janak, M. 1998). Generally lighting simulation packages involve a lengthy learning effort, which restricts their use to expert designers, and they are computationally costly for general architectural and engineering purposes, especially during the initial design stage. In order to reduce the computational burden the daylight coefficient method has been suggested as a third approach (Tregenza,P.R. and Waters, I.M. 1983; Reinhart, C.F. and Herkel, S. 2000).

The tool described in this article encompasses an integrated thermal and lighting simulation approach for evaluating the impact of daylight and dynamic shading device design on energy demand. The amount of input is small yet it provides detailed hourly output of the daylight level, the electrical energy consumption for lighting, heating load, cooling load and indoor operative temperature. An existing simplified thermal simulation tool BuildingCalc (Nielsen, T.R. 2005) and a daylight simulation tool LightCalc (Nielsen, T. 2005) formed the starting point for the work.

\section{Calculation procedures}

There are several different methods and tools for determining daylight distribution in rooms. Methods vary from simple factor calculations through radiosity methods to complex computer algorithms, such as ray-tracing. In this tool, the radiosity method is employed for internal daylight reflections, while the incident initial light is calculated using a ray-tracing approach. This gives a reasonable balance between accuracy and calculation time. 


\subsection{External light distribution}

External daylight may be divided into direct light from the solar disc, diffuse light due to the scattering properties of the atmosphere, and diffuse light reflected from the ground and surroundings. The diffuse light is modelled using the approach in Robinson and Stone (2006) and summarized here. An upper sky dome for atmospheric light and a lower (inverted) sky dome for ground reflections (one above and one below the horizontal plane) are used to model diffuse light. Each sky vault is divided into 145 patches using a discretization scheme proposed by Tregenza (1987). Each patch subtends a similar solid angle $\Phi(\mathrm{Sr})$, which enables every patch to be treated as a point source with insignificant error. The sky vault is divided into seven azimuthal bands of equal angular height $\left(\sin \gamma_{\mathrm{i}, \max }-\sin \gamma_{\mathrm{i}, \mathrm{min}}\right)$, in which the azimuthal range $\Delta \alpha$ increases towards zenith $\left(12^{\circ}, 12^{\circ}, 15^{\circ}, 15^{\circ}\right.$, $\left.20^{\circ}, 30^{\circ}, 60^{\circ}\right)$.

$$
\Phi_{i}=\Delta \alpha_{i}\left(\sin \gamma_{i, \max }-\sin \gamma_{i, \min }\right)
$$

Let $L$ denote the luminance $\left(\mathrm{Lm} \mathrm{m}^{-2} \mathrm{Sr}^{-1}\right)$ of the $i$ 'th patch, $\xi$ the mean angle of incidence (rad), and $\sigma(0 \leq \sigma \leq 1)$ the visible proportion of the patch, then the illuminance $E_{s k y}$ on an external plane due to diffuse light from the sky vault is expressed as:

$$
E_{s k y}=\sum_{i=1}^{145}(L \Phi \sigma \cos \xi)_{i}
$$

Let $E_{n}$ denote the direct normal illuminance and $\xi$ the incidence angle (solar zenith angle), then the illuminance on an external inclined plane due to direct light $E_{\text {sun }}$ is expressed (Scharmer, K. and Greif, J. (2000):

$$
E_{\text {sun }}=E_{n} \cos \xi
$$

Having determined the light sources, the reflecting ground can be represented as a luminous up-side down sky with constant brightness. Given the ground patch luminance $L^{*}$, the illuminance due to reflected light $E_{\text {ground }}$ is written as:

$$
E_{\text {ground }}=\sum_{j=i}^{145}\left(L^{*} \Phi \sigma \cos \xi\right)_{j}
$$

where $L^{*}$ is expressed as a function of the total horizontal diffuse illuminance $E_{s k y}$, the direct illuminance $E_{\text {sun }}$ on a horizontal plane and the mean ground reflectance $\rho$ (albedo):

$$
L^{*}=\frac{\rho}{\pi}\left(E_{s u n}+E_{s k y}\right)
$$

The Perez anisotropic sky model (Perez et al. 1993) is amenable to implementation in a computer program while maintaining good overall performance. The luminance of a sky point $L_{i}$ is given here:

$$
L_{i}=\frac{l v_{i} d h}{\sum_{j=1}^{145}(l v \Phi \cos \xi)_{j}}
$$

where the relative luminance $l v$ is normalized to diffuse horizontal illuminance $d h$ as recommended by Perez et al. (1993). Diffuse horizontal and direct normal illuminances are obtained from measured horizontal and direct normal irradiances respectively by a luminous efficacy $\eta$ given in Perez et al. (1990).

The visible proportion $\sigma$ is calculated by establishing a 10x10 grid of each patch and evaluating the visibility of each grid point for all internal surfaces. Thus $\sigma$ is a function of both distant objects (other buildings, the landscape) and near shades like the window recess and overhang. Reflected light from opposing building façades is not yet treated.

\subsection{Internal daylight distribution}

The calculation of the internal distribution of light is based on the luminous exitance method. This method is analogous to the radiosity method, in that all the restrictions and assumptions are the same. Internal subsurfaces hit by transmitted direct and diffuse light act as light sources, with the initial exitance $M o$, if we assume these 
surfaces have Lambertian optical characteristics and reflect incident light perfectly diffusively and ignore any specular properties. The methodology and implementation of the daylight distribution algorithms are described in detail by Park (2003).

\subsection{Coupling of external and internal light distribution}

To establish the initial light exitance $M o$ of a subsurface the amount and the direction of the light and the reflectance of the surface has to be known. Therefore the external and internal light distributions is coupled in a simple ray-tracing approach that assumes the luminance of the sky hemisphere and ground hemisphere patches can be considered as point sources.

\subsubsection{Diffuse light}

For diffuse sky and ground light penetrating into the room, the exitance for each internal subsurface is calculated using eq. (2) and eq. (4) multiplied by the profile-angle dependent light transmittance $\tau_{\theta}$ and the surface reflectance $\rho$ :

$$
M o_{i}=\rho\left(\sum_{i=1}^{145}\left(L \Phi \sigma \cos \xi \tau_{\theta}\right)_{i}+\sum_{j=1}^{145}\left(L^{*} \Phi \sigma \cos \xi \tau_{\theta}\right)_{j}\right)
$$

The profile angle $\theta$ is defined as the line of elevation projected unto the vertical normal plane of a surface. We may also name it the perpendicular incidence angle on a vertical surface. The profile-angle dependent light transmittance is used because it is calculated directly by the WIS program (van Dijk, D. and Oversloot, H. 2003), see section 2.4. However for clear glazings with isotropic optical properties we use the profile-angle dependent data directly as dependent on incidence angle.

\subsubsection{Direct light}

For direct light a different approach is applied. It is evident that all direct light transmitted through the glazing hits a subsurface. Subdividing the internal surfaces, however, may result in false prediction of the amount of incoming direct light. Let $E_{d i r}$ denote the incident sun light on the window plane obtained by eq. (3), $A_{g}$ the glazing area, $A_{j}$ the area of the $j$ 'th internal subsurface and $m$ the total number of internal subsurfaces. If we define a normalization factor $\chi=E_{d i r} A_{g} \tau_{\theta} / \sum_{j=1}^{m} E_{n} A_{j} \tau_{\theta} \cos \xi_{j}$ then the initial exitance $M o$ of the $i$ 'th subsurface is written:

$$
M o_{i}=E_{n} \rho_{i} \tau_{\theta} \cos \xi_{i} \chi=E_{d i r} A_{g} \rho_{i} \tau_{\theta} \frac{\cos \xi_{i}}{\sum_{j=i}^{m} A_{j} \cos \xi_{j}}
$$

When the direct light is transmitted through the glazing, some of the direct light may be transformed into diffuse light in a diffusing device, e.g. blinds placed in conjunction with the glazing. This effect is taken into consideration by calculating the light contribution from sun, sky, and ground on the window plane by using eq. (2), (3), and (4). The exitance of the inner glazing surface $M o_{g}$ is determined by multiplying the total light contribution with the light transmittance for direct light that is diffused when it passes the glazing/shading system: $\tau_{d i r \rightarrow d i f}$. This light transmittance is calculated by WIS, see section 2.4 .

$$
M o_{g}=\left(E_{\text {sun }}+E_{\text {sky }}+E_{\text {ground }}\right) \tau_{\text {dir } \rightarrow \text { dif }}
$$

Devices that redirect the incoming light, e.g. a specular light shelve are modelled using a simple implementation. It is achieved by setting a special redirecting light transmittance $\tau_{\text {redir }}$ to a value between 0 and 1 where 0 means that no light is redirected and 1 that all incoming light is redirected. This means that for an incoming ray of light with a given profile angle $\theta$ the following applies: $\tau_{\theta}+\tau_{d i r \rightarrow \operatorname{dif}, \theta}+\tau_{\text {redir, } \theta}=1$ (FIG. 1). The inclination angle $\beta$ of the slat or light shelve determines the reflection angle. Only fully specular devices are considered and any specular interreflections between slats and between slats and glazing are ignored. 


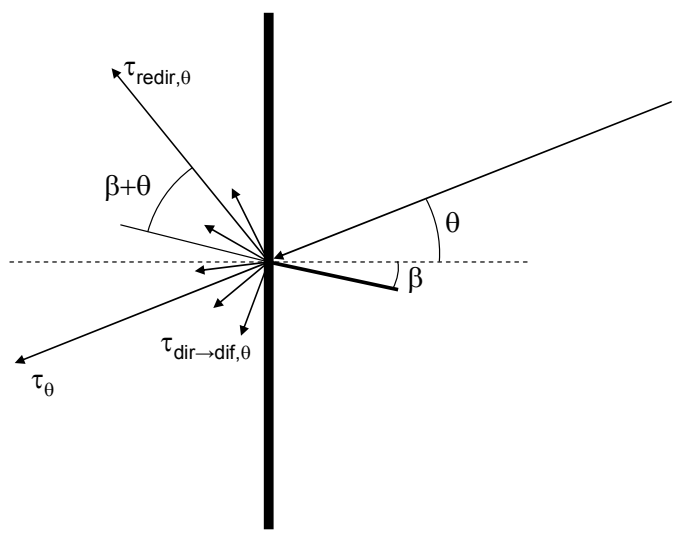

FIG. 1. Illustration of how an incoming ray of light from the sky, sun or ground is transmitted directly, diffused in the combined glazing and shading, or redirected specularly with equal inbound and outbound angle.

\subsection{Light transmittances}

A critical element in the daylight calculation routine is the light transmittance of the combined glazing/shading system. For this purpose the European software tool called WIS (van Dijk, D. and Oversloot, H. 2003) is used. This tool implements algorithms from the ISO standard 15099 (ISO 15099 2003) capable of calculating the light transmittance of a transparent system for both direct and diffuse light.

WIS calculates the thermal and solar performance of multilayered window systems, allowing the user unlimited combinations of glazing and solar shading devices. This makes WIS a very powerful tool for evaluating various integrated daylight designs. Currently the improvement and verification of WIS, and its database format and database population are the responsibility of the EU Thematic Network WinDat, which consists of major European research institutions and manufacturers of window components.

The output from a WIS calculation may be in the format of a text file. The file includes the light transmittances and solar energy transmittances for different solar profile angles $\left(-90^{\circ}\right.$ to $90^{\circ}$ at $10^{\circ}$ increments), and may be loaded seamlessly into the tool described in this article. If the shading device has multiple shading positions, e.g. Venetian blinds, the user may generate and load files for every position required. The tool will linearly interpolate between the transmittance data loaded, thus making the number of loaded positions a question of desired accuracy.

Because the employed method of calculating incident light on internal subsurfaces is equivalent to a ray-tracing technique, the WIS transmittance for direct light is employed for both diffuse and direct light. WIS cannot yet handle specular shading devices, e.g. light shelves or light redirecting devices.

\section{CONTROL STRATEGIES}

\subsection{Thermal simulation}

The simplified thermal model is described in detail in Nielsen (2005). It is capable of evaluating the thermal indoor environment and heating and cooling loads in a building with very few input parameters while providing the option of sophisticated controls.

\subsection{Electrical lighting}

The electrical lighting system can be divided into general and task lighting. Both systems are defined by the power consumption of the lighting fixtures in $\mathrm{W} / \mathrm{m}^{2}$ when providing an illuminance of 100 lux, and the minimum (standby) power consumption. The linear relationship is shown on FIG. 2. The values for power density and corresponding illuminance are often supplied by the producers of lighting fixtures, and the maximum illuminance is calculated using the maximum power density. 


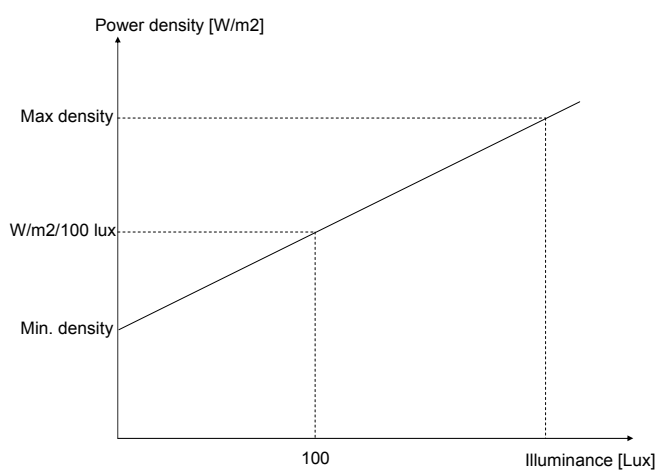

FIG. 2. Definition of illuminance and power density relationship for lighting systems in the tool.

Both systems can be defined and controlled separately with respect to daylight in two arbitrary points within the simulated enclosure. The possible control strategies are 'always max', 'always min', 'on-off', and 'continuous'. The hourly incoming daylight in the point is evaluated and the electrical lighting is switched on/off or dimmed according to the chosen control strategy. The 'on-off' control switches between the maximum and minimum power consumption when the daylight level is below or above the illuminance setpoint. The 'continuous' control interpolates linearly between the maximum and minimum power consumption in order to meet the specified setpoint. Electrical losses in the ballasts must be included in the power density.

\subsection{Shading}

The indoor air temperature controls the systems including the shading. This means that shading is activated only when excess heat gains occur, thus ignoring the risk of glare for the time being. In the case of screens or similar, the controls are limited to screen up or screen down.

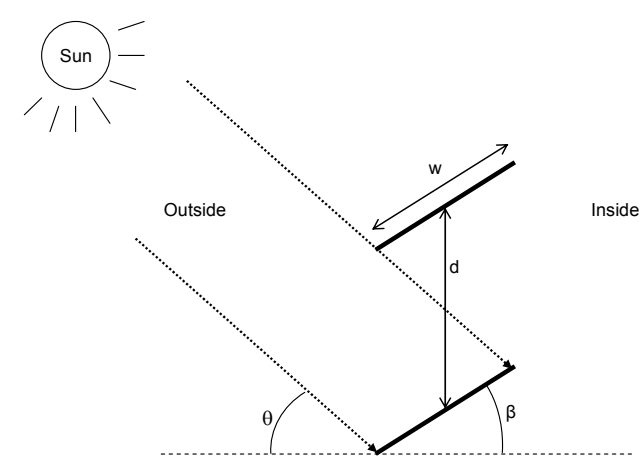

FIG. 3. Illustration of the cut-off shading control strategy for adjustable slats.

In the case of adjustable slats or similar the shading is lowered and adjusted to 'cut-off' angle when the indoor air temperature exceeds the specified cooling setpoint. Let $d$ denote the distance between two slats (m), $\theta$ the profile angle of the sun (degrees), and $w$ the width of the slats (m), then the cut-off angle is calculated:

$$
\beta_{\text {cut off }}=\arcsin \left(\frac{d \cos \theta}{w}\right)-\theta
$$

\subsection{Thermal simulation coupling}

It requires a sophisticated coupling to calculate the incoming daylight, the effect of shading on daylight levels, and thus electrical lighting consumption and indoor air temperature. This is achieved by pre-calculating the hourly daylight levels in the room without shading, initiate the thermal simulation, evaluate the hourly indoor operative temperature with respect to the cooling setpoint, possibly lower the shading and adjust the slat angle (for blinds) to cut off direct sunlight, and calculate the daylight levels again. If the operative temperature still exceeds the cooling setpoint, venting, increased ventilation, and mechanical cooling are employed in that order. The daylight levels are evaluated at two arbitrary points specified by the user. 


\section{Validation}

Of the numerous lighting simulation programs available, Radiance has been extensively validated and repeatedly surpassed competing programs in terms of both functionality and accuracy. For these reasons, we chose Radiance as our reference model. The validation of the daylight calculation algorithm is carried out for a single office room as depicted on FIG. 4. Three different setups are carried out for a clear glazing, external blinds adjusted to cut-off angle and an external screen. The property data is listed in TABLE. 1

TABLE. 1: Input data for validation.

\begin{tabular}{lllll}
\hline Properties & WIS Code & Property & Value [-] & Remarks \\
\hline Glazing & 4-15Ar-SN4 & Light transmittance & 0.782 & Double glazing w/ lowE coating \\
Blinds & Windat \#01 & Diffuse reflectance & 0.096 & Slat width: 0.08m, slat distance: $0.072 \mathrm{~m}$ \\
Screen & Verosol Silverscreen & Light transmittance & 0.035 & Total transmittance for screen+glazing \\
\hline
\end{tabular}

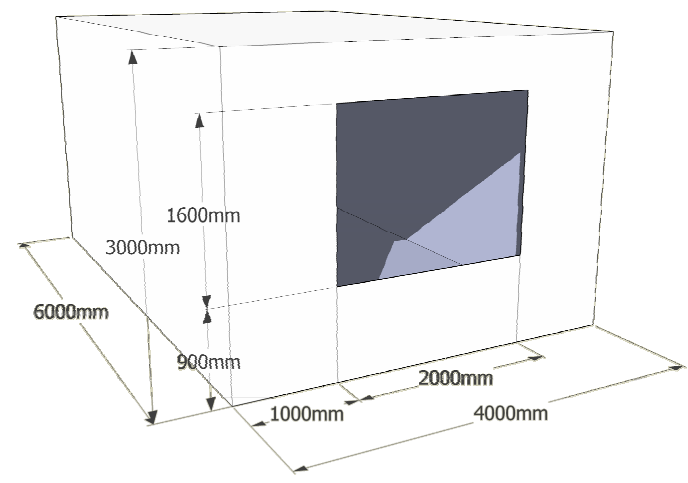

FIG. 4. Room dimensions for validation.

The chosen validation date is the $21^{\text {st }}$ of September at 3 p.m. because it involves complex calculation of solar position, incidence angles and cut-off angle. The radiation data is from the Danish Design Reference Year and the measurements are performed at desktop height $0.85 \mathrm{~m}$ in interval points along the centre line of room.

FIG. 5 to FIG. 7 compares the illuminance levels computed by Radiance and by the simple tool. The relative error is within $\pm 20 \%$ for the clear glazing and for the blinds which is considered satisfactory in daylight research. However the largest discrepancy is for the screen, but this is due to two facts: the light transmittances from WIS are unidirectional but screens have bidirectional properties and the screen is defined in Radiance as a glazing with reduced transmittance ignoring the diffusing properties of the real screen.

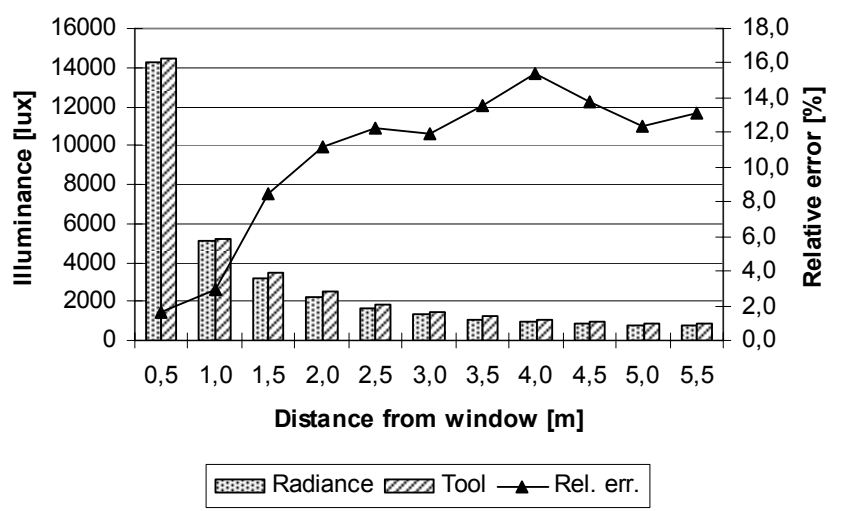

FIG. 5. Clear glazing. Absolute illuminance levels and relative error. 


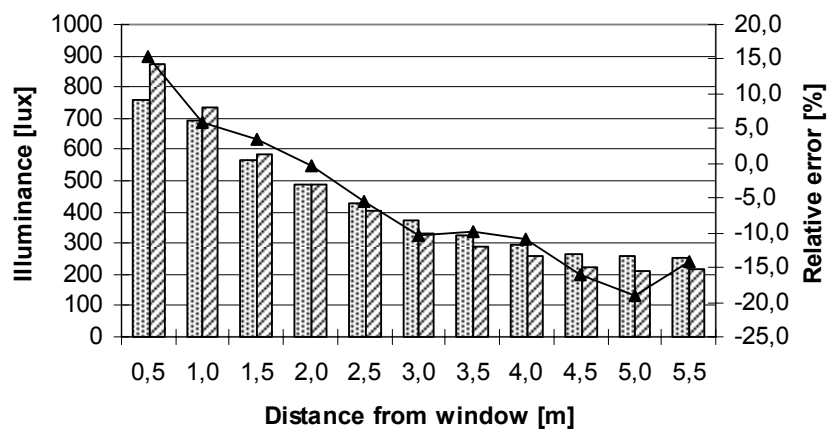

gadiance $\square$ Rool $\leadsto$ Rel. err.

FIG. 6. External blinds at cut-off angle. Absolute illuminance levels and relative error.

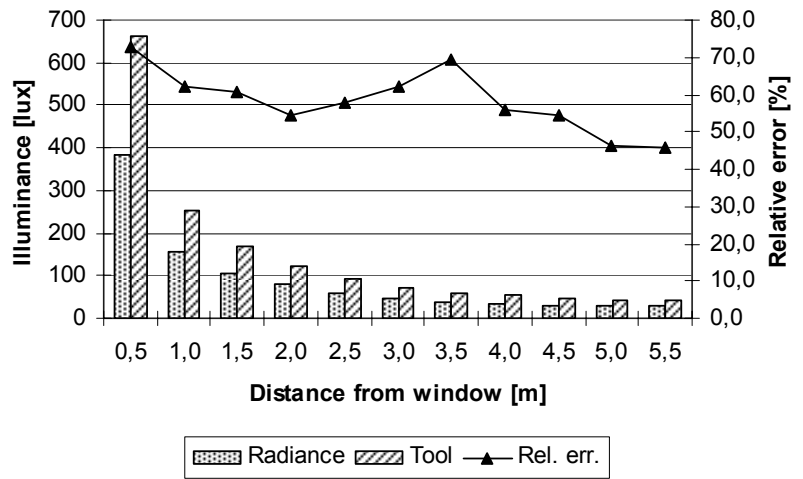

FIG. 7. External screen. Absolute illuminance levels and relative error.

\section{Combined simulation}

FIG. 8 depicts the implications of daylight responsive lighting systems. The artificial lighting system adjusts continuously with respect to the incoming daylight complementing the illuminance deficit. If overheating occurs the shading device is activated and the effect on daylight, casual gain and the thermal balance is quantified. Consequently the tool aids in producing daylight friendly design and quantifies the effect of 'smart' solar shadings that allows the maximum amount of direct sunlight to be tranferred diffusively in order to save electrical energy.

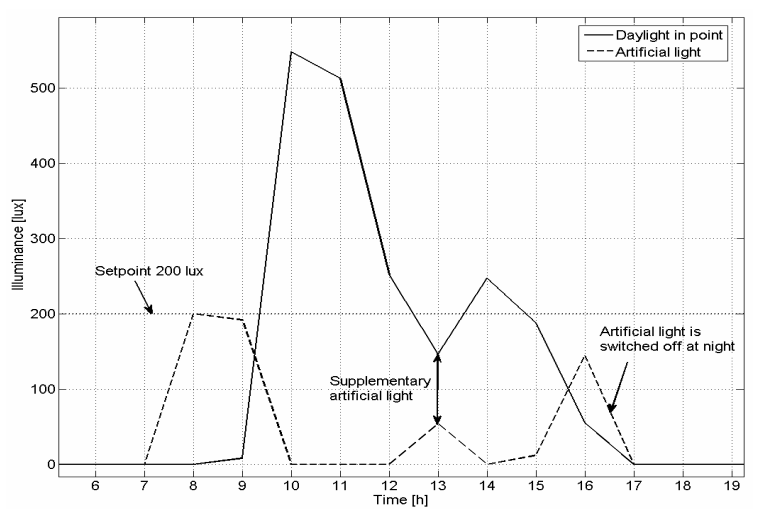

FIG. 8. Daylight and artificial light in a point. Continuous dimming control of the lighting system.

\section{Conclusion}

The tool described here is developed to evaluate the impact of incoming daylight on the energy consumption for lighting. The tool calculates the daylight distribution on the basis of a ray-tracing approach and the radiosity 
method to enhance accuracy while maintaining calculation speed. The sky is divided into patches with individual luminances in order to imitate the energy distribution of the real sky. Rays are traced from each individual sky patch to the surfaces of the room through glazing and shading giving the initial input to the radiosity algorithm which is employed for internal light distribution. Window overhang and recess as well as distant objects like other buildings reduce the visible proportion of the sky.

The daylight distribution is calculated every hour, thus providing the information necessary for the thermal program to control the photoresponsive lighting and to calculate the heat load of the electrical lighting system. The daylight and thermal simulations are integrated meaning that the indoor temperature is recalculated if overheating has caused the shading to be activated.

The daylight algorithms were validated by comparison with the state-of-the-art ray-tracing program, Radiance, using the Perez anisotropic sky. The results show agreement within $20 \%$ relative error, thus the simplified tool is adequate for predicting the electrical energy consumption of photoresponsive lighting systems, including the impact of complex shading systems such as external Venetian blinds.

\section{References}

Clarke, J. and Janak, M. (1998). Simulating the thermal effects of daylight-controlled lighting. Proceedings of Building Performance (BEPAC UK), Issue 1.

Fraunhofer-Institut für Bauphysik, 2006. ADELINE 3.0, Abteilung Wärmetechnik, Stuttgart, Germany. Available from: http://www.ibp.fhg.de/wt/adeline/

ISO 15099 (2003). ISO 15099:2003 Thermal performance of windows, doors and shading devices - Detailed calculations, International Organization for Standardization, Geneva, Switzerland.

Nielsen T.R. (2005a). Simple tool to evaluate energy demand and indoor environment in the early stages of building design, Solar Energy, Vol. 78, No. 1, 73-83.

Nielsen, T., Nielsen, T. R. and Svendsen, S. (2005b). Calculation of daylight distribution and utilization in rooms with solar shadings and light redirecting devices. Proceedings of 7th Symposium on Building Physics in the Nordic Countries, 1011-1018.

Park K.-W. and Athienitis A.K. (2003). Workplane illuminance prediction method for daylighting control systems, Solar Energy, Vol. 75, No. 4, 277-284.

Perez R., Ineichen P., Seals R., Michalsky J. and Stewart R. (1990). Modeling daylight availability and irradiance components from direct and global irradiance, Solar Energy, Vol. 44, No. 5, 271-289.

Perez R., Seals R. and Michalsky J. (1993). All-weather model for sky luminance distribution - preliminary configuration and validation, Solar Energy, Vol. 50, No. 3, 235-245.

Reinhart C.F. and Herkel S. (2000). The simulation of annual daylight illuminance distributions - a state-of-theart comparison of six RADIANCE-based methods, Energy and Buildings, Vol. 32, No. 2, 167-187.

Robinson D. and Stone A. (2006). Internal illumination prediction based on a simplified radiosity algorithm, Solar Energy, Vol. 80, No. 3, 260-267.

Scharmer, K. and Greif, J. (2000). The European Solar Radiation Atlas. École des Mines de Paris, France.

Tregenza P.R. (1987). Subdivision of the sky hemisphere for luminance measurements, Lighting Research \& Technology, Vol. 19, No. 1, 13-14.

Tregenza P.R. and Waters I.M. (1983). Daylight coefficients, Lighting Research \& Technology, Vol. 15, No. 2, 65-71.

van Dijk, D. and Oversloot, H. (2003). WIS, the European tool to calculate thermal and solar properties of windows and window components. Proceedings of IBPSA, Building Simulation, Vol. 1, 259-266.

Ward, G. L. and Shakespeare, R. A. (1998). Rendering with Radiance - The art and science of lighting visualization. Morgan Kaufmann, San Francisco. 